\title{
RACISM: PROCESSES OF DETACHMENT, DEHUMANIZATION, AND HATRED
}

BY FARHAD DALAL, PH.D.

The author looks at definitions of racism from the viewpoints of various theoretical frameworks, addressing the role of projection and other phenomena. Racism is then examined according to principles of psychoanalytic relational theory, attachment theory, and radical group analytic the ory. Power relationships, the psychosocial process, a sense of us versus them, and the universal importance of a feeling of belonging are also taken into consideration. In examining the meaning of race, the author addresses the notions of black and white and their evolution over time, as well as the phenomen on of othering.

A colleague described an experience while traveling on a train during a visit to London. She became aware that she was the only white person in the carriage, and this made her feel frightened and completely alone. This was a remarkable experience because, patently, she was not alone; she was in a carriage full of people.

What is going on? How is it that she feels alone when patently she is not? Is this kind of experience "racist"? And if so, why?

I do not stand in judgment of my colleague, because I can recognize myself having such experiences continually. Sometimes these differentiations are innocuous or humorous; at other times,

Some material for this article is drawn from a book by the author, Race, Colour and the Process of Racialization: New Perspectives from Group Analysis, Psychoanalysis and Sociology (Dalal 2002). 
critical and deadly. The triggers vary hugely: sometimes, color; at other times, beliefs, attitudes, behaviors or something else altogether. This is a way of saying that, in focusing on race and racism, I am not suggesting that this is the primary difference or the only meaningful difference that needs to be attended to. In fact, what I am going to put forward is part of a general theory of difference -in which the fiction called race is but one element.

This short vignette speaks to the first of my four questionsjust what is racism? My other questions are: How does psychoanalysis tend to explain the phenomenon of racism? Third, how can attachment theory be used to think about racism? And fourth, how and why is it that attachment theory is located outside psychoanalysis by psychoanalysts themselves, as much as by attachment theorists? I will not speak in a neat, linear fashion to each of the questions in turn, as the answers to one problematize the others.

\section{WHAT IS RACISM?}

Is racism a pathology that only some are afflicted with, or is it endemic to the human condition so that all of us are subject to it? Is it the case, as was said in some circles in the 1970 s and is sometimes repeated now, that only whites can be racist? And what of the function of racism-is it something destructive or something useful, an adaptive mechanism that has evolved?

Racism tends to be described in two sorts of ways: The first description is at the level of the social world, where it is noted that racism is a form of organizing peoples, commodities, and the relationships between them by utilizing a notion of race. The second description begins in the world of emotions, and indicates that racism consists of the feelings of hatred, disgust, repulsion, and other negative emotions felt and expressed by one group for another.

Now, in general, psychoanalysis tends to look for the causes of things that take place in the "external" social world by examining the goings on of the "internal" psychological world of individuals. For example: 
- "A group consists of individuals in a relationship to one another; and therefore the understanding of [ the individual's] personality is the foundation for the understanding of social life." (Klein 1959, p. 247)

- "All sociological problems are ultimately reducible to problems of individual psychology." (Fairbairn 1935, p. 241)

- "The basis of group psychology is the psychology of the individual, and especially of the individual's personal integration." (Winnicott 1965, p. 146)

It follows, then, that psychoanalysis is bound to look for explanations of racism (that is, explanations of antipathies between peoples taking place in the social world) in the internal world of individuals. We can see that the question of "What is racism?" cannot be separated from speculations about its causes.

Psychoanalysis offers four different kinds of explanations for adult behaviors in general. The first explanation is akin to transference in the sense that Freud first spoke of it: repeating without remembering. Here, events and behaviors in adult life are said to be repetitions and versions of patterns laid down during infancy and childhood. If these developmental events are repeatedly experienced as traumatic, then the adult will behave in disturbed and sometimes aggressive, perhaps racist ways.

The second kind of explanation draws on the individual/ group dichotomy. What might be said here is that racism is some kind of group phenomenon that sweeps up individuals into its path through the process of contagion or something similar. In this way of thinking, good people find themselves behaving badly because of being swept up by the group. According to this way of thinking, when in groups, individuals lose their civilized sensibilities and revert to some primeval, savage state.

The third type of explanation postulates that we are driven to act in certain ways by our biological and genetic inheritancespecifically, the instincts. And the fourth explanation, by far the 
most common place, features the mechanisms of splitting, repression, and projection.

I will begin my critique with the last of these.

\section{PROJECTION}

The idea of projection lies at the heart of most psychoanalytic explanations of social phenomena, generally, and proceeds in the following way: difficulties arising in the internal world of an individual (say, for example, aggressive impulses), which cannot be managed for whatever reason, are split off from consciousness, repressed, and projected into some object or person in the external world. The subject now comes to experience the object/ person as difficult in itself (in this instance, aggressive).

This theory works well, but in a limited way, at the level of a particular individual. This theory explains why it is that this or that particular individual has hateful feelings toward blacks or some other group of people. However, it does not explain how and why it is that a whole group of people should simultaneously come to hold hateful feelings toward certain other groups. There is also the issue of why black people, rather than (say) nurses, should come to be used as containers for these unwanted and problematic aspects of the self. And why is it that, in one context, black people come to be these receptacles, while in another context, Protestants do, and so on.

One answer to these challenges, sometimes put forward in psychoanalytic writings, is that these groupings have previously been "socially sanctioned" as deserving of these projections, and so are al ready denigrated. But this response actually avoids the central issue, which is: how do these groupings come to be socially sanctioned in a particular way in the first place?

Further, this kind of explanation does not address what happens to the unwanted aspects of the individuals who constitute these denigrated groups-blacks, Jews, or women, for example: where are they to project the problematic aspects of their psyches? Are they not going to be allowed the same privilege as the non- 
denigrated groups of getting rid of problematic aspects of their internal worlds through the mechanisms of splitting and projecting? In sum, what this powerful theory does is to say that the psychological mechanisms of individuals exploit preexisting social conditions in order to manage internal psychological difficulties; but it does not engage with the problem of how those social conditions-specifically, racism-came to be generated in the first place.

\section{SIMILARITY AND DIFFERENCE}

Notions of similarity and difference have become buzzwords in this territory. However, in the analytic literature, notions of similarity and difference are rendered curiously asocial, as though all differences were equivalent. They are not. A stranger knocking unexpectedly at the door will elicit quite different associations and emotions, depending on whether he is a young black man or a white man in a suit. Other determining variables are the person opening the door and the location of the door. In other words, one cannot leave the context out of the analysis. There is no such thing as a stranger in the abstract-strangers are always particular, embodied and situated. Of course, animosity is by no means the "natural" or inevitable response to meeting a difference; reactions are bound to be predicated on the meanings attributed to, and associated with, that difference. Thus, the particularities of the social context cannot be left out of the analysis, if our examination is not to become reductive.

We are never just strangers to each other; we are also simultaneously familiars. Let me put it this way: between any two individuals, there is an infinity of similarities and differences. I am similar to you by virtue of at least one attribute, and, in the same moment, I am different by virtue of at least one other attribute. Thus, similarities and differences are not absolutes, and neither are they opposites. The experience of similarity and difference can always be deconstructed. For example, in this moment, do you experience me as similar to or different from you? On what basis 
- race, culture, ethnicity, gender, or some other category? If you experience me as similar, why are you inclined in that direction at this moment, and what have you done with the differences? And if you are experiencing me as different, what have you done with the similarities? Why?

Positivist ways of thinking about similarity and difference have become taken for granted and unquestioned in our professionit would appear that people are either similar or different to each other. For example, Basch-Kahre (1984) takes it for granted that it is a universal truth that one is inevitably afraid of strangers. Her explanation for this is that sources of the fear of strangers are to be found early on in the individual's developmental story, when the baby seeks to keep the father out of the picture by making him unknown and therefore a stranger. This repressed memory is said to be reactivated in adult life with the appearance of any stranger, which results in the projection of the old hatred toward the father onto contemporary strangers. She says: "This happens when [ we are] confronted with people and cultures in which we can discover no similarity with ourselves" (p. 62, italics added). But, clearly, this is an impossibility-that there could be "no similarity" between this analyst and her analysand. We have to ask of the analyst a deeper question: how does the analyst manage the extraordinary feat of experiencing "no similarity"? Recall the vignette at the start of this paper.

In sum, the overwhelming majority of papers in the psychoanalytic literature treat the topics of racism and prejudice as a symptom-as the external effect and social expression of internal psychological dynamics. But, as Littlewood and Lipsedge (1989) note, "projection is a mechanism, not an explanation" (p. 29).

\section{THE RELATIONALISTS}

Relationalists, like Fairbairn (1935) and Winnicott (1965), shift their attention from instinct to relatedness, from breast to face, from individual to dyad. In their way of thinking, the sources of problematic adult behaviors are to be found in the particulars of the 
individual's developmental story. The thinking here is that people behave cruelly to others later in life because they have been dealt with cruelly in early childhood.

I would go along with the relational view for a considerable way, but, once again, it is an explanation at the level of a particular individual and his or her developmental story. For this kind of explanation to be valid at a societal level, as would be necessary for a phenomenon like racism, the developmental processes of a large number of members of a society would have to be finely synchronized. Surely, this is not a realistic scenario. Further, this explanation does not account for the occasions when racism flares up in previously convivial contexts in which various groups of people have coexisted for many generations.

Another instance of this kind of theory is provided by Chasseguet-Smirgel (1990). She seeks to explain the sources of Nazism by positing the existence of a universal developmental stage, which she calls the archaic oedipal matrix. According to her, when in this stage, one is said to find it difficult to tolerate difference, and so seeks to merge with mother-i.e., to be the same as mother. But, in the fullness of time, this matrix is supplanted by the normal oedipal matrix, after which it is possible to accommodate difference.

Chasseguet-Smirgel then suggests that the German nation was for a time "stuck" in the archaic matrix, where Nazi ideology found its sources. According to her, Nazi ideology is actually the wish for the body of the German people (the Aryans) "to become one with the body of the Mother (the German homeland, the whole earth)" (Chasseguet-Smirgel 1990, p. 171). For this merging to proceed, the body of the German people had to be made pure - that is, homogenized-and so all differences (as exemplified by the Jew, the homosexual, and so on), as obstacles to this union, had to be purged and annihilated: "In order to form a single body, its constituent cells must be identical, purified of all foreign elements liable to impair its homogeneity" (p. 171).

As noted, such a theory can be valid at the societal level only in the event that a whole nation of individuals were to fall prey to the archaic matrix at about the same time, with many or most of 
them failing to complete the proper resolution of such a complex. And then, miraculously, at a certain later time, much of the nation would simultaneously come to resolve the complex. Another problem with this kind of theory is that it has taken for granted the idea of being Jewish as foreign, different and opposite to that of being German. Questions avoided by this kind of analysis are: How was it that the Jew came to be thought of as alien to a vision of Germanness? What is the ontological status of the category A ryan, and from whence did it come? And so on.

Interestingly, much of psychoanalytic thinking has been reluctant to allow the external social world to play a causal role in the structuring of internal distress, and, instead, is more likely to explain difficulties in the external social world as due to, and driven by, distress in the internal world. For instance, Basch-Kahre (1984) says that the explanation for her black African patient's "deep feeling of being worthless whenever the theme of the stranger was brought up ... [ was to be found in] his experience of weaning and with his oedipal conflict" (p. 65). The fact that the patient was unable to advance in his job was explained completely by this feeling of inferiority-in other words, the state of his internal world. No thought is here given to the external circumstances that (a) might contribute to his sense of inferiority, and (b) might make it hard for him to advance on a practical level. While his particular experience of weaning no doubt played a significant role in the structuring of his feelings of worthlessness, no space is given to the possibility that components of his worthlessness might also have to do with particular experiences of living as a black man in a predominantly white European country.

Not only does the literature tend to explain the external by the internal; it also often tends to interpret engagements in the external social world as a type of pathology or as an acting out. For example, M yers (1977) understands his black female patient's increasing involvement with black militant groups as a flight from her rage toward him. But one could construe the patient's new capacity for involvement with such groups as a sign of increasing health and self-esteem born of the analysis. Further, M yers reports 
that the patient's self-esteem indeed increased following this involvement, as revealed in her dreams; however, he does not give any credit to her involvement in the external dimension for her internal changes: "While some of this [ gain] was related to modifications in the patient's self-esteem as a result of the analytic work, a good deal of it was related to her intense need to deny the underlying degraded black self-representation" (p. 173). In other words, the patient's improvement was in part real because of the analytic work, and in part false because it stemmed from the repression of her "degraded black self-representation."

Another instance is found in the description by a black psychotherapist, D. E. Holmes (1992), of her patient Miss A, who was also black. Miss A's presenting complaint was the so-called irrepressible urge to take part in the race riots in her city. $\mathrm{H}$ olmes says that, through their work together, they "came to understand her protestations as warded-off self-loathing, which itself was in part a defence against recognition of her rage, the threatened eruption of which had brought her to treatment" (p. 3). Thus, political rage is understood as a displacement of the patient's real internal and personal rage. It is at the very least curious that her selfloathing is understood only as a defense, and not as a symptom of living in a racist context.

My intention is not to dismiss internalist psychoanalytic explanations of social phenomena out of hand, but rather to point out their limitations. I find these ways of thinking useful and essential to my clinical work; however, when they are put forward as the only explanations and pose as being complete, then they lose value and become dangerously reductive-in which case, they do not so much explain as explain away.

Theories (no less than people!) do not fit neatly into boxes. I have perhaps added to the confusion here by speaking of the relationalists in the same breath as Basch-Kahre and ChasseguetSmirgel. In fact, in the foregoing, one finds two distinct ideologies. The theories of the relationalists Winnicott and Fairbairn would tend toward the belief that racist behaviors and hatreds in general, as manifested in later life, find their genesis in things hav- 
ing gone wrong in the developmental process; this, then, logically leads to the proposition that only some people turn out to be racist. Meanwhile, the Basch-Kahre and Chasseguet-Smirgel models propose that racism is a natural outcome of a universal developmental process, so that all people are prone to it.

Confusingly, I find myself agreeing with aspects of both: with the latter thesis that we all find ourselves engaging in racist practices (but not for the reasons suggested by these models); and I also agree with the relational thesis that the developmental processes are driven by the specifics of our actual lived experiences, rather than by fantasies.

In what follows, I will propose a way of thinking that directs us toward resolution of this contradiction. But before that, let me attend to attachment theory.

\section{ATTACHMENT THEORY}

Although attachment theory in its classical form shares much common ground with psychoanalytic relationalists' thinking, it is distinct from theirs in that it prioritizes the idea of attachment over that of relationship. Attachment theory indicates that psychological relationships are generated by and through the biological processes of attachment, which are themselves generated by evolutionary processes to ensure that caregiver and the vulnerable young stay in close proximity to each other.

Attachment theory is also close to the theory of the instinctivists in that, in both schemata, the first impetus of the infant is generated by its biology. In fact, one could say that all three of these formulations are instinctivist, in a sense, with the differences being the differing aims of the instinct according to each schema: for instinctivists per se, the aim is to discharge; for relationalists, to relate; and for attachment theorists, to attach.

Of course, the word instinct here means simply that we are biological beings that have our evolutionary history written into our bodies. Theoretical disputes focus on just what is written into the body and how fixed it is. I am inclined toward a stance akin to the 
relationalist, intersubjectivist, and attachment schemata, rather than toward those that make hypothetical notions like the death instinct central to their cogitations.

The first thing to be said is that the so-called secure base in an individual's developmental history should not really be referred to in that way; rather, it should be called simply the base-because, although one is bound to attach to it, it is not always experienced as the source of security per se. As attachment theory tells us, we do not have a choice about whether or not to attach; we cannot help but attach, however vile or neglectful the base may be. Imagine the torture of having to hold onto something that is too hot for comfort in order not to fall to one's death, and then think of the conflicting impulses that one would have to contend with; such a scenario gives quite a good idea of the psychological scars in which this kind of attachment experience would result.

Problematic attachment histories lead to the generation of avoidant, ambivalent, or disorganized patterns of relating to others. In these instances, the mode of interrelating becomes a mixture of being preoccupied with the self while being avoidant and/ or hypervigilant toward others. Often, aggression surfaces as a means of coping with difficulties in the internal world. These terms -avoidant, hypervigilant, aggressive, and so on--are frequently found in descriptions of racist phenomena. So, if one were to think of racism as a pathology, as a symptom and a sign of something's having gone wrong in the developmental process, then, according to this theory, it is here in this grouping that we would look to find its sources and genesis.

This way of conceptualizing the problem suggests that securely attached persons are not likely to be racist. De Zulueta (1993), arguing from a broad relational/ attachment perspective, says:

Racism . . . begins, as all acts of dehumanization, by a distortion of perception .... . This cognitive process originates ... from the experience of abuse which the infant or child attempts to ward off by identifying with the aggressor .... The seeds of ... racism ... . are sown in the emotional wounds of the abused and traumatized. [p. 244, italics added] 
De Zulueta goes to the limits of the hypothesis to assert that racist beliefs can "only take [hold] ... where the psychic template of dehumanization already exists" (p. 244, italics added). By using the term only, she argues that developmental difficulties are a necessary condition (but not sufficient) for racist behavior to occur. But if this were true, then how is it that, even on occasions when the developmental process has gone adequately well, we find people behaving in racist ways? Something has escaped our efforts to examine the situation. I very much agree with de Zulueta that those with problematic early attachment histories are perhaps more likely to behave in ways that we might call racist; and, although I would consider her very much an ally in terms of the arguments I develop, my point of disagreement with her is this: that while problematic developmental histories can be (and often are) contributory, they are neither necessary nor sufficient for racist phenomena to emerge.

I want to stress again that I do not dispute that difficulties during the early part of the developmental process will have a significant impact on possibilities and behaviors in adult life. No doubt, if one were to probe the developmental history of Dr. Shipman (a medical doctor in the United Kingdom who was responsible for the deaths of hundreds of elderly patients over many years), for example, one would find events that could reasonably be said to have contributed to his psychic structure and behavior. However, the fact that racism, in the sense I have described it, grips all of us at different times suggests that one needs to extend the theoretical frame in order to be able to more fully consider the nature of racism. This would be like asking ourselves: how would we set about explaining a nation of Dr. Shipmans?

It is for these reasons that it seems to me that, in its first and classical form, attachment theory shares the same weaknesses as that of the relationalists, in that, although the world taken account of is interpersonal and external, it is not yet social. The relationships and attachments that are spoken about continue to take place in a sociological vacuum, and, further, they take place between biological entities, like mother, child, father, sibling, and so on. 
In contrast to those of other schools of psychoanalysis, contemporary attachment theorists have specifically set about testing their hypotheses in other cultures and contexts. In doing so, they acknowledge that the shape of the infant's developmental process is formed by and mediated through the cultural systems in which this takes place. It follows, then, that each cultural system will generate its own forms of attachment, which legitimate different ways of being together. This is akin to the multicultural ethos of respecting differences- the idea that we are equal but different. But I think that one needs to go even farther than this and engage with the problematic of power.

In my opinion, the schema best positioned to help us engage with the notion of power is that of Foulkesian group analysis, and in particular the radical version of it (Dalal 1998, 2002). In what follows, I will briefly introduce relevant group analytic thinking, and then use it to offer an elaboration of attachment theory in order to make new sense of racism.

\section{RADICAL GROUP ANALYTIC THINKING}

I will introduce four elements from radical group analytic theory that are pertinent to the subjects under discussion-specifically, from the works of psychoanalyst and group analyst S. H. Foulkes $(1948,1964)$ and sociologist Norbert Elias $(1976,1978,1991,1994)$.

\section{Power}

The first element, power, is extensively addressed by Elias. He argues that power is an inescapable aspect of all human relationships. And this is so because, as human beings, we are interdependent. Interdependence is another word for function or need. To say that person $A$ has a function for person $B$ is to say that $B$ needs $A$. And if $B$ needs $A$, then $A$ has power over $B$. However, the reverse will also be true, though not in the same way.

Hegel (1967) famously showed that the slave is not entirely powerless; the master needs the slave, even if only in the minimal sense of the slave's continued existence in order for the master to 
continue as exploiter. One can see in the foregoing example, then, that the relationship between $A$ and $B$ is interdependent, even while it is also bound to be asymmetrical. A constrains $B$-and vice versa; it is this kind of enabling constraint that is described as power relations. Elias $(1976,1978,1991,1994)$ notes that power is not a thing that one individual possesses and another does not; no one can be completely powerless or completely powerful. Power is, first and last, a relational attribute. Thus, we can say that all relationships are of necessity power relationships.

\section{The Psychosocial Process}

The second element consists of a challenge to the metapsychological assumption that the social and psychological worlds are fundamentally different levels of existence. Elias dissolves this dichotomy. He does not propose the more limited idea that these two regions influence each other, because this would be to retain an idea of the two regions as separate. Rather, his statement is more fundamental: that the social and psychological are two aspects of the same process.

Foulkes $(1948,1964)$ offers a helpful analogy. Imagine that you and I are each driving on our particular journeys. In this, we are akin to autonomous individuals. But soon we both end up in a traffic jam, and it now appears to each of us that "something outside me" is "acting against me," "preventing me" from exercising autonomy. The name that we give to this kind of experience-an experience that we actually help to create, to sustain, and remain integral to-is society.

\section{III. "I" and "We"}

The third element reverses the usual arrangement between the individual and the social. As we have already seen, the logic of psychologies that prioritizes individuals over society leads us to think of the social subject, we, as secondary, something that is constituted by the coming together of a number of preexisting individual subjects, the I's. Specific forms that societies take are 
therefore said to be driven by the goings on in the internal worlds of individuals coming together.

Radical group analysis reverses this to say that the I is constituted by the varieties of we that one is born into. Each of us, as a particular individual, is born into a preexisting society constituted by a multiplicity of overlapping and conflicting cultures. The cultures themselves, as well as the relationships between cultures, are constituted by power relationships. As we grow and develop, we imbibe, of necessity, the preexisting cultural forms, habits, beliefs, and ways of thinking around us. These introjections are not taken into an already-formed self; rather, they come to contribute to the formation of that self. Further, because the relationships between the varieties of we are of necessity power relationships, then we can say that the I-the me-is constituted at the deepest of levels by and through the power relationships that are part of the social fabric one is born into.

Foulkes $(1948,1964)$ is not espousing a kind of social determinism in which human beings are mere pawns of social forces. As will become clear, to think in the way described does not mean denying the existence of individuals, each with his or her unique sense of self, nor denying that all are biological beings in bodies.

\section{Belonging}

The fourth element concerns the notion of belonging. Foulkes asserts that there is a fundamental need in all human beings to belong - to be part of an us-as a condition for psychological wellbeing. But even to put it in this way, to say that there is a need to belong, misrepresents the situation, as it implies that there is a possibility of not belonging. In fact, we cannot not belong.

\section{SOCIALIZING ATTACHMENT THEORY}

Returning now to attachment theory, I would like to point out that the ideas introduced above via radical group analytic theory are not unfamiliar to contemporary attachment theorists, such as Fonagy 
(2001) and J. Holmes (1993). Fonagy believes that the child comes to form its sense of self through internalizing the picture in the parent's mind of the child's state of mind. He says that this is the mechanism through which the child comes "to form the core sense of himself" (2001, p. 175).

However, the parent does not just experience the child per se, but rather as a particular kind of child. The parent, like all of us, will be led to particular ways of experiencing the world according to the conventions written into the discourses we inhabit. For example, it is a widely accepted finding that caregivers tend to treat male offspring more favorably than female ones. It has been found that, even while teachers imagine that they are giving equal amounts of time and attention to pupils of both sexes, the males tend to get more. Along another axis, it is not uncommon for the arrival of darker-skinned children to be less welcomed than that of Iighter-skinned children in many Asian and Afro-Caribbean families (Fletchman Smith 2000).

I do not wish to imply that all female and all darker-skinned children might be universally, uniformly, and inevitably denigrated, as this would be a form of social determinism-a concept that I do not subscribe to. One reason things are not so fixed is that we inhabit multiple discourses at the same time, discourses that continually contest and subvert each other. But the point is that we are never outside our discourses; we are never in an ideologyfree zone.

It seems to me that the caregiver reflects back to the infant much more than a picture of the infant's state of mind as it exists in the caregiver's mind. The caregiver is also giving back to the infant the caregiver's attitude toward the infant, which comes in turn to inform the growing infant's attitude toward itself, its self-esteem. Central to my thesis is that the attitudes of the caregiver are severely constrained by the discourses that have formed the caregiver's self. These attitudes being reflected to the child exist outside the scope of the caregiver's consciousness; otherwise, our consciousness could not take the forms that it does. Foulkes calls this grounding, which is taken for granted and which forms our responses, thoughts, and experiences, the social unconscious. 
A similar view is found in attachment theory. Liotti (1987, cited in J. Holmes 1993) calls these schemata super conscious, rather than unconscious, and says that they are the organizing principles that "govern the conscious processes without appearing in them" (J. Holmes 1993, p. 170). In a similar vein, what I am arguing is that the image of the self taken in by the infant from its caregivers is, from the first moments, intrinsically social-by which I mean that the infant is never just an infant per se to itself, but rather a particular infant who, by virtue of its attributes, finds itself situated and positioned in the caregiver's affections, and so comes eventually to similarly situate and position itself.

This means that one may no longer draw a dichotomy between a social self and a personal or true self, because the personal self is intrinsically social. Hume (1748) was onto something similar when he speculated that there is no such thing as a self outside, beyond, or prior to the attributes that one can name about the self.

This way of thinking - in which the external social world and the things that actually go on between people are given a fundamentally formative role in the creation of what takes place in the so-called internal world of individuals-is anathema to certain psychoanalytic orthodoxies, in which there is a tendency to give developmental primacy to a notion of fantasy over lived experience. Clinical training programs grounded in these traditions teach novices to read the patient's descriptions of actual, enacted events as signs and ciphers pointing to the workings of the psychological world; and if the therapist treats these descriptions more straightforwardly (by which I do not mean a naive acceptance), as playing a causal role in their own right, then it is taken to be the case that the therapist has been seduced by the patient, and has capitulated in some way.

This worldview has a very powerful grip on our profession, so much so that even analysts who give credence and weight to so-called external differences, such as color, tend to talk of these differences in terms of their use by the patient as defenses, and to characterize successful therapies as moving past these external differences to some deeper level, to engage with the "real" person 
behind these categories. Indeed, the attention paid to the lived external world in an attachment-theory approach is one of the reasons why this theory is sometimes viewed with hostility and contempt by certain groups within psychoanalysis.

In the foregoing, I have been leading up to the idea that the so-called social categories of identity (in general) are integral to a deep sense of self, the experience of the true me. And, if we accept this, then it follows that, in attaching to others, we are also, of necessity, attaching to categories, however subliminal our sense of those might be. ${ }^{1}$

Actually, attachment is not a strong enough word, because it suggests a picture in which two preexisting selves secondarily come to attach to each other. But what is actually being suggested and described by Fonagy (2001), Foulkes (1948, 1964), and others is the radical idea that there is no self prior to processes of attachment and introjection, and that the infant's self is constructed through the attachment processes themselves. To restate this in group analytic language would be to say that who I am is the same as where I belong. We can see, then, why it is that, when the social identities one finds oneself imbued with are trampled on, tampered with, trivialized, denigrated, or dismissed in some way, one is powerfully affected; such experiences are likely to be perceived as attacks on one's integrity and as a violation of the sanctity of one's being.

To reinforce the point: we do not just attach to people; we also attach to categories. However, thinking in these terms may make things in the internal world appear more fixed than they actually are, as I shall discuss in what follows.

\section{MAKING A DIFFERENCE}

The preceding discussion renders the world too simple on two counts: First, it takes categories of belonging, such as white, Mos-

${ }^{1}$ Cole (2005) develops further arguments concerning our relationships to categories- this time, those based on sexual orientation. 
lem, and so on, to be facts that straightforwardly exist out there in the world. Second, the categories have been described as though they are homogenous unities. I will unpack these simplifications and begin with two premises: (1) that we cannot not attach, nor can we not belong, and (2) attachment and belonging are aspects of the same process.

The idea of belonging is paradoxical in that, for the experience of belonging to be meaningful, two conditions must be fulfilled: First, in order to belong to one group, it is necessary for there to be another one not to belong to. Second, it has to be the case that only some may belong to the group, and others are not allowed to belong. If these two conditions are not fulfilled, then the belonging category becomes infinitely large, encompassing everything and everybody, and so becomes meaningless.

In other words, intrinsic to the notions of attaching and belonging is the negation of something and someone. Winnicott (1965) alluded to a similar idea when he described the infant's first I am moment, in which it gathers itself together, as a paranoid moment. This is because the infant, in collecting elements from the environment with which to form itself, simultaneously repudiates other elements. In a sense, the infant is saying to the not-me elements: "You don't belong." Having made this gesture, the infant now fears attack from the repudiated elements, and thus comes the paranoia.

Winnicott suggests that we groups come about through a very similar mechanism: repudiation of the elements designated as notwe. Or, to put it another way, a we can exist only in contrast to a them. Or, putting it still another way, even as one makes a gesture of inclusion in one direction, at the very same moment, one cannot help but make a gesture of exclusion toward every other direction.

Let me add here two well-known jokes, which are really parables:

1. A woman gives her husband two ties. When she sees him wearing one of them, she exclaims, "So-you did 
not like the other one!" When I was first told this, I understood the moral of the story to be that, in choosing one thing over another, we are not necessarily condemning that other. But, over time, I have come to think that a negation of some sort is in fact taking place here-precisely because, in that moment, one object has been chosen over the other. The two ties are different and not equal.

2. A devout orthodox Jew found himself marooned on an uninhabited island. When he was rescued many years later by a passing ship, the rescuers were astonished to see that he had built himself a synagogue to worship in. But then, as they rounded the island, they were further astonished to see a second synagogue. Mystified, they asked the castaway why he had built two synagogues. He replied that one was the synagogue he went to, and the other was the synagogue he did not go to.

Fortified by these parables, I will now elaborate further.

It is important to keep in mind that it is always impossible to identify just what the essence is of any particular us-say, Britishness. When we look directly at the British us, we find not homogeneity, but heterogeneity: vegetarians, whites, landlords, Kleinians, Scots, blacks, football hooligans, accountants, Christians, Moslems, fascists, liberals, and so on. And if one turns one's attention to each of these subgroupings, they, too, dissolve into further arrays of diversity. I think it is precisely because of the impossibility of finding and naming the essence of the us that one looks to the margins-to the not us.

Accordingly, the us is defined not so much by what it is as by what it is not. The structuralist Saussure (1959) said pretty much the same thing, that "concepts are purely differential and defined not by their positive content, but negatively by their relations with the other terms of the system. Their most precise characteristic is in being what others are not" (p. 117). And there is no unity to be found in the not us either. 
In sum, the impression of difference and otherness between us and them is as illusory as is the impression of solidity and cohesion within us and them. However, these illusions are nonetheless powerful, and come to have a life as facts, both in our psyches and in our engagements with each other. They come to have a particular kind of reality.

Given the fragility of these ways in which we belong, as well as the fact that there is an infinity of alternative belongings continually available to each of us, we are prompted to ask: How and why do we come to experience one encounter as taking place across a difference, and another as within a region of similarity? What leads us to assert that the psychotherapy taking place between Mr. Smith and $\mathrm{Dr}$. Singh is multicultural, while that between Mr. Smith and Dr. Jones is not? As noted earlier, it is quite possible to frame both encounters in terms of similarity as well as difference.

The answers to these questions, I would say, have to do not with the nature of the differences themselves, but with the functions that the processes of differentiation are being employed to perform. It is not the case that one simply finds a difference, which one then finds oneself responding to. Rather, one finds oneself emphasizing certain differences in order to create a differentiation. The questions that should constantly be asked are: Given the infinity of differences (and similarities) between two human beings, how and why are we led in a particular moment to experience and construe one difference as primary and to render the others less meaningful? What-and importantly, whose-purpose is being served by making the differentiation here rather than there? We should remember that differences are evoked in order to make a differentiation-and, more specifically, a differentiation between the haves and the must not haves.

All societies, all cultures, are not homogeneities, but rather are structures of power relations in which different groupingseach with its own agendas and beliefs-contest each other. For example, not only are Brahmins going to have a very different experience of $\mathrm{Hindu}$ culture than that of the Untouchables, but there are also going to be variations in the experiences of one Brahmin from another. 
Now, it is precisely because of the fluidity of these boundaries that the danger of one sort of us dissolving and reorganizing into another sort of us is ever present; and so continual work is required to shore up and bolster the us. This work takes several forms. One bit is done for us silently and automatically by our cognitive mechanisms. Social scientists have demonstrated that when the mind uses an attribute to make groupings out of continuities, there follows a kind of hallucination in which it seems to us that those within each of the groupings appear to be more similar than they actually are, and that the gap between the groupings appears to be greater than it actually is (Brown 1988, 1995; Turner and Giles 1981). This cognitive hallucination is necessary for the formation and experience of categories (see Dalal 1998, 2002).

But this silent shoring up is not enough to maintain solidity of the us, and so the emotions are called into play to help maintain distance between us and varieties of them. The primary additional mechanism is one in which the them are denigrated, while the us are idealized. The notions of denigration and idealization, being absolute (good and only good, bad and only bad), create the impression of an antithetical dichotomy between us and them-a dichotomy with a vast intermediary chasm. In other words, this process has created the illusion of types.

One of the most prodigious of these illusory typologies is the one we call race

\section{BUT WHAT IS RACE?}

Whatever race is, it is used to sort varieties of humankind. I mplicit here is the apparent truism that there are different kinds of humans to be sorted. But, in fact, when one tries to examine the notion of race, it disintegrates. The attempts to define and distinguish race (physiology) from culture (behavior and beliefs) and from ethnicity (the internal sense of belonging) continually fail, as the attempted definitions of all continually collapse into each other. 
Bailey's (1996) definition is a particularly telling one: "The term 'Ethnic Minority' is much debated, but includes a wide variety of races and cultures, both black and white" (p. 89, italics added). This failure to make and sustain distinctions between the three termsrace, culture, and ethnicity-highlights the idea that there is something problematic about the attempt to divide up humanity in this way. However, curiously, notions of black and white have been used from very early on to characterize all three categories; we talk easily of black and white races, cultures, and ethnicities. This observation serves as a prompt to now shift our attention to notions of black and white.

Is it not curious that the people whom we call black and white are not actually chromatically black and white? How do they come to be so named? Through tracing the semantic history of the words black and white in the English language, one discovers that the words started off as relatively neutral. (See graph on the following two pages, "Semantic History of the Words Black and White.") Over the last millennium, the two terms have increasingly gathered associations of negativity and positivity, respectively, as is evident from the graph. There are two periods in which there were dramatic bursts of new associations to the terms: the Middle Ages (the time of the Crusades), and from the sixteenth century onward (the beginning of the imperial adventure).

It is surprising to discover how recent so many of these associations are. The association of black with dirt was first recorded in 1300 a.d., with death in 1400, with immorality in 1552, and with evil in 1581. Eventually, elements that can have no color, like negative emotions, began to be called black, from the seventeenth century onward. This last point is a particularly telling one: as the world became increasingly color coded, so did the psyche.

There is a double movement here: on the one hand, the attachment of black to a thing lends that thing a negative value, impelling one to push it away; and, on the other hand, things imbued with negativity are increasingly perceived as "naturally" having something black about them. The conclusion I draw is that blackness gets attached to a thing in order to cathect it with repellence, and the converse becomes true of whiteness. 


\section{SEMANTIC HISTORY OF THE \\ 0 AD \\ $500 \mathrm{AD}$ \\ 1000 AD}

Neutral: color, etc.

Uses of

Black

Neutral: clear, color, silver

Symbolic of spiritual purity, $71 A D$

Uses of White

BLACK AND WHITE Initially used primarily as adjectives 


\section{WORDS BLACK AND WHITE}

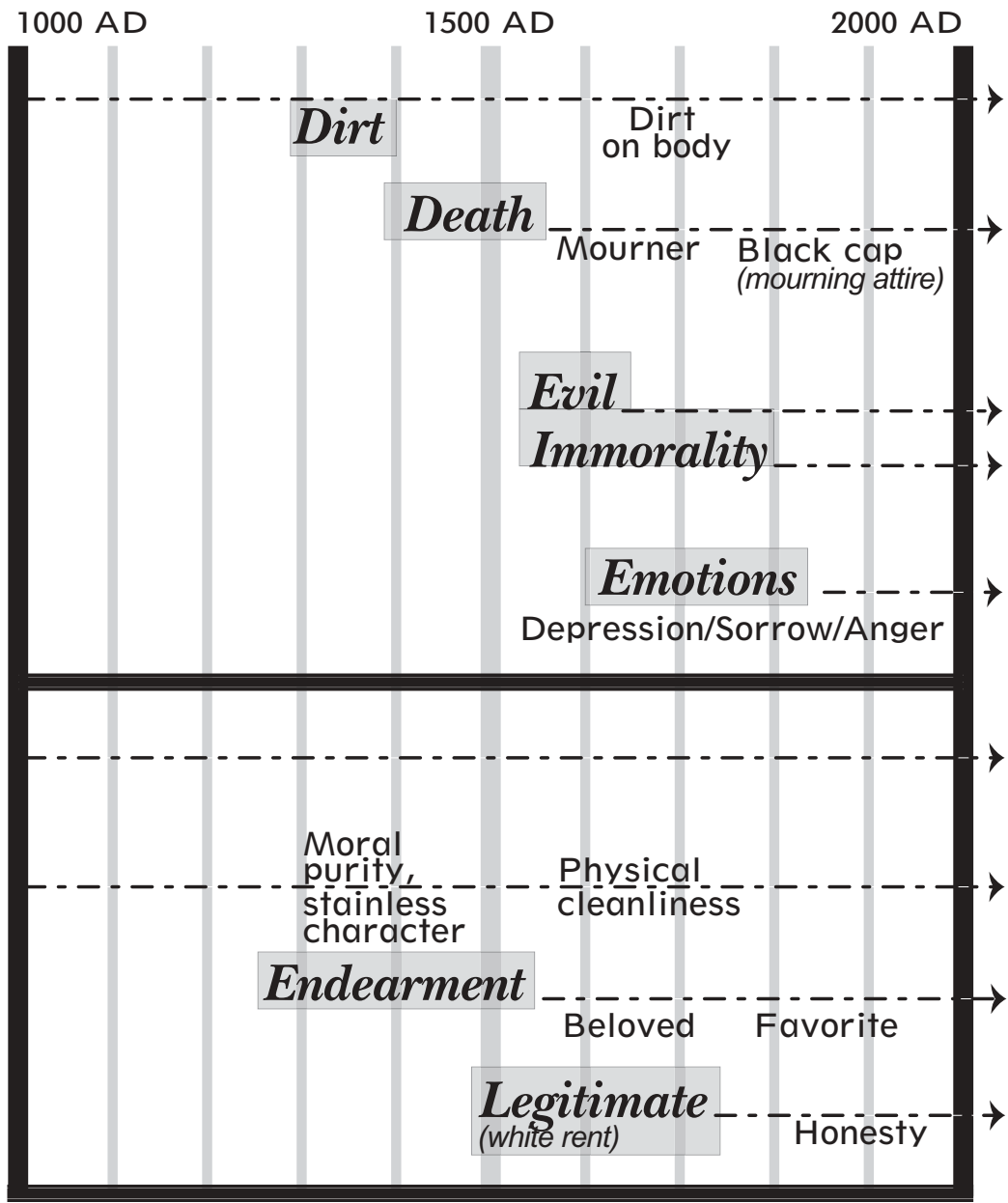

APPLIED TO PEOPLE

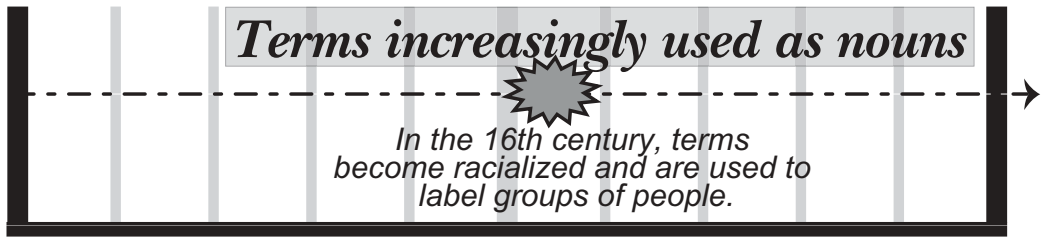


For example, it is surprising to discover that, in English, the so-called Black Plague of the thirteenth century was not called the Black Plague until the nineteenth century. Similarly, the Black Prince was first so called 200 years after his death. It is my contention that, during this epoch, notions of white and black became honed into powerful tools that could be used to lever things-and people-into territories designated as good or bad, in or out, us or them. These terms became instruments of inclusion and exclusion. The hollowness of race as a category is one of the reasons that it has come to rely on something that appears more substantial (that is, notions of black and white), in order to sustain itself.

Black and white were first used to name races-that is, as nouns for people of different types - in the sixteenth century. By this time, the words had already been loaded up with many of the associations that they have continued to bear. Thus, the naming of people as black or white is not so much a descriptive act as an othering process-a racializing process.

Something very similar is taking place with the seemingly more innocuous terms culture and ethnicity. It is no coincidence that people designated as black were first given the name black by those who designated themselves as white. But there was no "done deal" here, either; for example, there were periods of time when enormous debates and struggles took place about whether the I rish were to be admitted to the category white, as was also the case for southern Europeans.

One of the troubles with the notion of race is that people tend to take its existence as fact, and to then use this thing called race to be, in itself, the source and explanation for racism. Why did riots occur in Chicago, or in Bradford? Answer: because of racial difference. The solution offered by the multiculturalists is to invite us to "tolerate" difference.

Meanwhile, some sociobiologists (e.g., Smith 1988; Van den Berghe 1988) explain away the situation through a four-stage argument based on the concept of the selfish gene (Dawkins 1976). They begin with the assertion that we are programmed by the evolutionary process to act in ways that will enhance the chances of our 
genes' survival and multiplication. Next, we are said to share more genes with kin than with not-kin, and this makes us automatically favor our own kin over others. Third, ethnicity or race is said to be an extension of kinship, and so we are thought to naturally favor those of the same race or ethnic group over others. And, finally, when we behave in these "natural" ways-we are accused of being racist

Here are some of the flaws in this argument: Any human grouping is found to have approximately $15 \%$ of its DNA patterns in common. This means that the other $85 \%$ is shared with the rest of humanity. So why should this $15 \%$ seek to favor its kin, and not the other $85 \%$ ? It is also the case that we share $98 \%$ of our DNA with chimpanzees-yet we do not treat them especially well. And, finally, we need go back only 150,000 years to find one of the common ancestors for all of humankind (Dawkins 1996) -thus, in a very real sense, we are all kin.

We are forced to return to the perplexing question: if there are no races, then what is racism? It seems to me that the only way to answer this is to say that racism is anything - a thought, feeling, or action-that uses the notion of race as an activating or organizing principle. Or, to put it another way, racism is the manufacture and use of the notion of race. It is evident that this definition of racism is one of activity; thus, I would say that more useful than the notion of racism is that of racialization - the process of manufacturing and utilizing the notion of race in any capacity. I am suggesting that the term racialization (with its emphasis on activity and an activity that requires our continual cooperation) captures the sense of the phenomena under discussion more accurately than the term racism (which has something passive in its connotations).

The fact that we inhabit a racialized and color-coded world means that, through the psychosocial developmental process, each of us, of necessity, imbibes a version of that world order, such that our psyches, too, become color coded and racialized. And then, in turn, we continue to reproduce and sustain the processes of racialization, despite our efforts not to do so. 


\section{PROCESSES OF OTHERING}

Fonagy (2001) comments poetically: "At the core of the mature child's self is the other at the moment of reflection" (p. 173). But this other at the core of the self is not really other because, by definition, it is part of the self. And, since it is part of the self, one recognizes the other in the self and the self in the other. Perhaps another term for this kind of recognition is empathy. To my mind, empathy is another way of thinking about these benign forms of attachment.

Now, whatever racism is, it is essentially a dehumanizing process through which an other is transformed into The 0 ther, from one of us into one of them. The racialized and dehumanized other is positioned outside the moral universe, with all its attendant requirements and obligations to fellow human beings. However, one of the points I have been arguing is that strangers are not encountered, but made-we estrange them. This act of othering, or estranging, in part consists of the activity of repressing, subjugating, and annihilating the similarities between self and other and the ways in which the other is known and understood.

One could call this a detaching process, through which differences are named and amplified in order to simultaneously create and detach from the them. Anything can be alighted on, and, once alighted, it seems ever so natural that that difference is anathema to us. Recall that in Gulliver's Travels (Swift 1726), two nations differentiated themselves and went to war on the basis of which end of a boiled egg should be broken into first.

In an arena such as this, then, the purpose of naming a difference is to make a division between the haves and the must not haves. When one difference weakens in our attempts to accomplish this task, we amplify others. For example, tales told by European adventurers during the late Middle Ages described Africans in Ianguage that we would today call racist. However, the word race was not used. To my mind, this was because there was no need to do so, as Africans were thought of as something not quite human. The notion of race made its entry at the point that it became clear 
that Africans are, in fact, part of humanity; then it began to be said that they might be human, but that they were of a different race. As the notion of race crumbled, the notion of culture was brought to the fore; what was then said was that we are all the same race, but we have different cultures. And, finally, ethnicity made its entry, once it became hard to sustain a meaningful distinction between cultural groupings-say, between Hindus and Moslems in India, or between Jews and Arabs in the Middle East. The categorical terms change from race to culture to ethnicity, but the process remains the same.

The fact is that the othering process is a work that is continually being done, because of the ever-present danger that some of them will become us. In part, this work consists of creating and maintaining a buffer of hatred, disgust, and contempt. But the fact that this work requires a continual engagement with them in order to estrange them means that perhaps the idea of detachment does not actually capture all of what is going on.

In order for a we to exist, the we need a them to continue to exist-but at a distance. Thus, the we need to be continually in touch with the them, paradoxically, in order to keep them at a distance. Could we say, then, that this kind of paradoxical keepingin-touch/ distancing is also a form of attachment? If we continue down this road, then could we say, too, that hate is a form of attachment?

The predicaments we have to continually live with and contend with are (at least) threefold: first, we cannot not divide; second, in order to belong and to be included, we are obliged, in that same existential moment, to exclude; and third, the lines along which we divide are by no means natural, however self-evident they might appear to be at times.

I will end with a quotation from Elias (1976):

[In] discussing "racial" problems, one is apt to put the cart before the horse. It is argued, as a rule, that people perceive others as belonging to another group because the color of their skin is different. It would be more to the point if one asked how it came to pass in this world 
that one has got into the habit of perceiving people with another skin color as belonging to a different group. [ $p$. xlvii]

I hope I have begun to answer the question of how it came to pass that we have gotten into the habit of perceiving people with another skin color as belonging to a different group, and then, indeed, into the habit of treating those persons differently.

\section{REFERENCES}

Bail ey, C. (1996). The health needs of children from ethnic minorities. In M eeting the $\mathrm{N}$ eeds of Ethnic M inority Children, ed. K. N. Dwivedi \& V. P. Varma. London: Jessica Kingsley, pp. 89-95.

Basch-Kahre, E. (1984). On difficulties arising in transference and countertransference when analyst and analysand have different socio-cultural backgrounds. Int. Rev. Psychoanal., 11:61-67.

Brown, R. (1988). Group Processes. Oxford, England: Blackwell.

- - - (1995). Prejudice. Oxford, England: Blackwell.

Chasseguet -Smirgel, J. (1990). Reflections of a psychoanalyst upon the Nazi biocracy and genocide. Int. Rev. Psychoanal., 17:167-175.

Col e, G. (2005). Categories as symptoms: conceptions of love in the psychoanalytic relationship. Psychoanal. Q., 74:977-987.

Dal al ,F. (1998). Taking the Group Seriou sly-Towards a Post Foulkesian Group Analytic Theory. London: Jessica Kingsley.

- - - (2002). Race, Colour and the Process of Racialization: New Perspectives from Group Analysis, Psychoanalysis and Sociology. Hove, England: Brunner-Routledge.

Daw kins, R. (1976). The Selfish Gene. Oxford, England: Oxford Univ. Press. - - - (1996). River out of Eden. London: Phoenix.

El ias, N. (1976). Introduction. In The Established and the Outsiders, ed. N. Elias \& J. Scotson. London: Sage, 1994.

- - - (1978). What Is Sociology? New York: Columbia Univ. Press.

- - - (1991). The Symbol Theory. London: Sage.

_- - - (1994). The Civilizing Process. Oxford, England: Blackwell.

Fair bair n, R. (1935). The social significance of communism considered in the light of psychoanalysis. In Psychoanalytic Studies of the Personality. London: Routledge, 1994.

Fl et ch man Smit h, B. (2000). M ental Slavery: Psychoanalytic Studies of Caribbean People. London: Rebus Press.

Fonagy, P. (2001). Attachment Theory and Psychoanalysis. London: Karnac. Foul kes, S. H. (1948). Introduction to Group Analytic Psychotherapy. London: Karnac Books, 1983. 
- - - (1964). Therapeutic Group Analysis. London: George Allen \& Unwin. H egel, G. W. F. (1967). The Phenomenology of M ind, trans. J. B. Baillie. New York: Harper Torch Books.

Hol mes, D. E. (1992). Race and transference in psychoanalysis and psychotherapy. Int. J. Psychoanal., 73:1-11.

$\mathrm{H}$ ol mes, J. (1993). John B owlby and Attachment Theory. London: Routledge. H ume, D. (1748). An Inquiry Concerning H uman Understanding. Oxford, England: Oxford Univ. Press, 1999.

KI ein, M. (1959). Our adult world and its roots in infancy. In Envy and Gratitude and 0 ther Works, 1946-1963. London: Virago, 1988.

Littl ewood, R. \& Lipsedge, M. (1989). Aliens and Alienists-Ethnic M inorities and Psychiatry. London: Unwin Hyman.

Myers, W. A. (1977). The significance of the colors black and white in the dreams of black and white patients. J. Amer. Psychoanal. Assn., 25:163181.

de Saussure, F. (1959). Course in General Linguistics, ed. C. Bally \& A. Sechehaye. New York: Philosophical Library.

Smit h, M. G. (1988). Pluralism, race and ethnicity in selected African countries. In Theories of Race and Ethnic Relations, ed. J. Rex \& D. Mason. Cambridge, England: Cambridge Univ. Press.

Swift, J. (1726). Gulliver's Travels. Chicago, IL: Holt, Rinehart \& Winston, 1967.

Turner, J. C. \& Giles, H., eds. (1981). Intergroup Behaviour. Oxford, England: Blackwell.

Van den Berghe, P. L. (1988). Ethnicity and the socio-biology debate. In Theories of Race and Ethnic Relations, ed. J. Rex \& D. Mason. Cambridge, England: Cambridge Univ. Press.

Winnicott, D. W. (1965). The Family and Individual Development. London: Tavistock.

de Zul uet a, F. (1993). From Pain to Violence- The Traumatic Roots of De structiveness. London: Whurr.

South Devon Psychotherapy and Counselling Service

4 Glenarm Terrace

Totnes, Devon TQ9 5PY

United Kingdom

email: farhad.dalal@devon psychotherapy.org.uk 